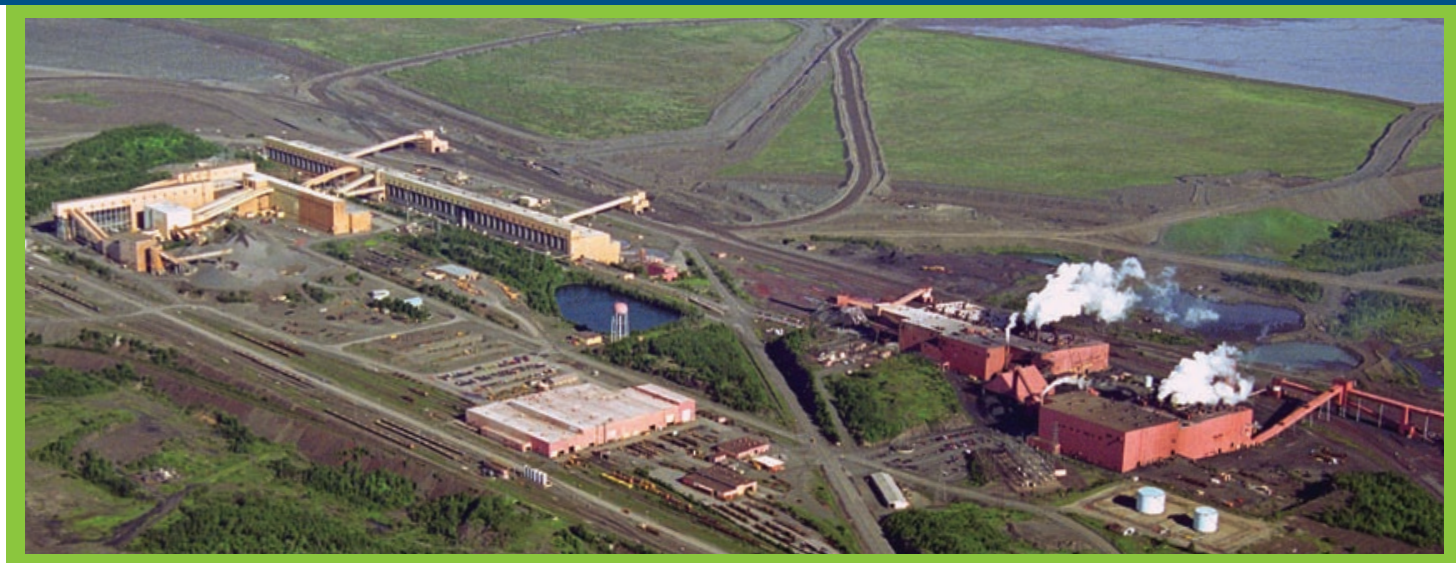

Located at Mt. Iron on the Mesabi Iron Range in northern Minnesota, the U. S. Steel Minntac plant produces approximately 14.5 million tons of taconite pellets annually.

\title{
Largest Producer of Steel Products in the United States Achieves Significant Energy Savings at its Minntac Plant
}

\section{U. S. Steel's Taconite Pellet Manufacturing Facility Improves Process Heating Efficiency and Rejuvenates Energy Savings Strategy Following Save Energy Now Assessment}

\section{Benefits}

Implemented \$760,000 in annual energy cost savings

Reduced annual natural gas consumption by

\section{5,000 MMBtu}

Achieved a simple

payback of 1.5 years

\section{Lowered emissions}

\section{Key Findings}

-When properly integrated in a system-level strategy, high-efficiency components can yield significant energy savings and non-energy benefits.

- The Save Energy Now energy assessment validated the decision to implement a project with large capital costs and demonstrated the value of similar measures.

- By upgrading burners in a kiln serving an important process line, the Minntac plant achieved significant energy savings, reduced maintenance, and improved production.

\section{Applications}

Process heating is used to heat and dry taconite pellets and represents a large share of the energy used by taconite processing plants. Improving the efficiency of the kilns that heat taconite pellets can provide significant energy savings and ensure reliable production.

\section{Summary}

In July 2006, a U. S. Department of Energy (D0E) Save Energy Now energy assessment was performed at U. S. Steel's Minntac plant in Mt. Iron, Minnesota, to analyze the efficiency of the plant's process heating systems and determine energy savings opportunities.
The assessment was conducted by DOE Energy Expert D. Paul Mehta, who worked with plant employees to evaluate the process heating systems using DOE's Process Heating Assessment and Survey Tool (PHAST). Multiple opportunities were identified that would yield significant energy savings across each of the process lines. In addition, the software tool helped validate existing natural gas savings resulting from a major burner system installation.

Before the assessment the Minntac plant had replaced 6 aging burners in a large kiln with 14 new, smaller, high-efficiency burners. During the assessment, the performance of the new burners and their impact on the process line's efficiency was evaluated. Using the PHAST tool, the Energy Expert confirmed the energy savings from the new burners and determined the potential savings from retrofitting the kilns in the plant's other process lines with such burner systems. The new burners are yielding annual cost and energy savings of $\$ 760,000$ and 95,000 MMBtu respectively. Additionally, the plant saves $\$ 30,000$ in annual maintenance labor costs. With project costs of approximately $\$ 1.2$ million, the plant achieved a simple payback of 1.5 years. 


\section{Project Drivers}

Energy efficiency is big concern for the Minntac plant. Prior to the assessment, the plant decided to upgrade the burners in a kiln serving one of their process lines not only for the energy savings, but also because the existing burners were well-worn and based on an outdated technology, and sometimes led to production shutdowns that damaged other process equipment. Because of the improved performance of the new burners, the plant is adopting a more proactive approach toward energy efficiency. They've helped form a corporate carbon dioxide and energy committee, headed by a corporate energy manager, which will provide guidance on energy efficiency across the company.

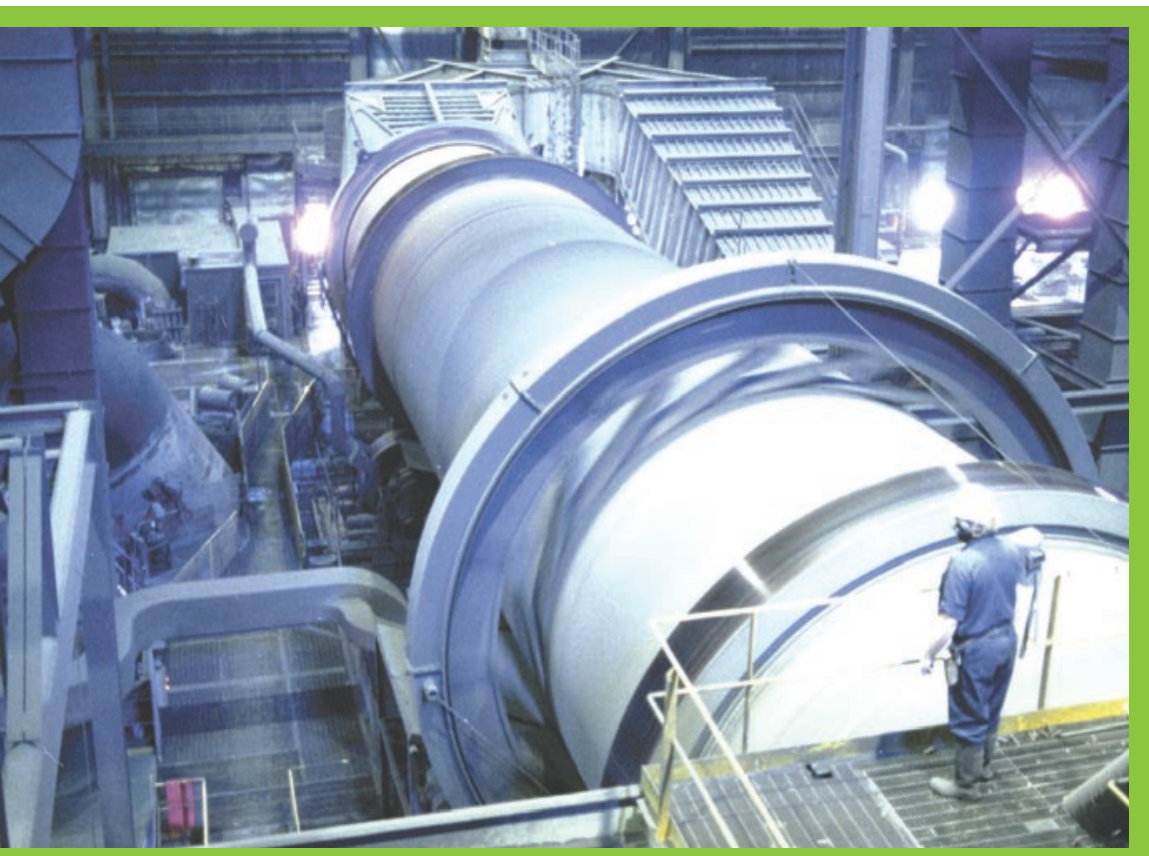

Process lines in the Minntac plant serve kilns that heat a mixture of taconite powder and clay at $2,450^{\circ} \mathrm{F}$ to create taconite pellets. After installing a high-efficiency burner in one of their process lines, Minntac saved $\$ 760,000$ and 95,000 MMBtu in natural gas.

\section{Company and Plant Background}

Founded in 1901, United States Steel Corporation (U. S. Steel) is the largest producer of steel products in the country. The company, which is headquartered in Pittsburgh, Pennsylvania, has 47,000 employees worldwide and manufactures a wide variety of high value-added steel sheet, tubular and tin products, as well as coke and taconite pellets. The company has a global annual raw steel capability of 31.7 million net tons and annual sales of approximately $\$ 16.9$ billion.

U. S. Steel's Minntac plant is part of the company's Minnesota Ore Operations, which also includes the Keetac plant. Both facilities mine and process iron-bearing taconite rock into taconite pellets for use in steelmaking. Each year, the Minntac plant's 1,200 employees produce approximately 14.5 million tons of taconite pellets. Process heating applications account for much of the Minntac site's energy use. Five process lines, each consisting of a kiln, preheater, and dryer, are used to process the taconite into pellets. These processes require high-temperature heat varying from $600^{\circ} \mathrm{F}$ to $1,000^{\circ} \mathrm{F}$ in the dryers, $2,200^{\circ} \mathrm{F}$ in the preheaters, and $2,450^{\circ} \mathrm{F}$ in the kilns. In addition, each process line is supported by large motor-driven systems such as draft fans, crushers, and mixers. Natural gas consumption at the Minntac plant was approximately 4.9 million MMBtu in 2007.

\section{Assessment Overview}

The assessment at U. S. Steel's Minntac plant was performed by a DOE Energy Expert who is a Qualified Specialist on the use of PHAST, a software tool developed by DOE for analyzing process heating applications. The Energy Expert formed an assessment team with the plant's lead process engineer and several employees, as well as managers, new employees, and engineers from other U. S. Steel plants. The team worked together to evaluate the Minntac plant's process lines and determine opportunities for energy-efficiency gains within them using the PHAST software.
"Minnesota Ore Operations was pleased to have been awarded one of the original DOE Save Energy Now assessments. We use a significant amount of energy at our operations, and we welcomed the recommendations of an unbiased energy professional relative to energy savings opportunities. The assessment confirmed that we were headed in the right direction with several projects we were working on and helped identify several other areas that we needed to take a closer look at." 
After gathering and analyzing the energy consumption data across the five process lines, the assessment generated nine potential energy savings opportunities. The team carefully reviewed each of these opportunities for technical and economic feasibility, and based on payback periods, classified each opportunity as either medium- or long-term. In the wake of the assessment, some of the estimated savings were updated based on more current information and further evaluation.

\section{Potential medium-term opportunities}

- Insulate Process Components-The assessment found that all the kilns, pre-heaters, and dryers were under-insulated with a maximum of 8 to 10 inches of refractory material and 2 inches of insulation. As a result, wall losses were determined to be approximately 407,000 MMBtu per year. By fully insulating all five lines, wall losses could be reduced by about $50 \%$, yielding annual natural gas savings of more than 203,000 MMBtu and cost savings of $\$ 1.6$ million.

- Reduce Infiltration-Because the kilns operate under negative pressure, the process lines consume approximately 119,000 MMBtu per year to heat the air that leaks into the kilns. By eliminating this infiltration, the plant could achieve natural gas cost savings of about $\$ 950,000$ annually.

- Use Fans with Higher Horsepower-The draft fans in several of the lines were less powerful than the draft fans that supply air to the kilns in the other lines. This caused the kilns in those lines to use more natural gas than the other kilns. By installing a more powerful draft fan in those lines, the assessment showed it would increase the kilns' convective heat transfer coefficient, causing them to use less fuel. This would result in natural gas savings of more than 88,000 MMBtu and cost savings of $\$ 709,000$ per year.

- Eliminate Leaks - During the walk-through portion of the assessment, a number of openings were noticed at several points within the process lines, especially around the peep-through doors. These openings led to convective and radiation heat losses. By fixing these openings it was estimated that the plant could achieve natural gas savings of about 44,000 MMBtu and cost savings of $\$ 350,000$ per year.

\section{Potential long-term opportunities}

- Use High-Efficiency Burners-High-efficiency burners were recently installed in one of the process lines. Based on prior energy consump- tion by that line, the assessment confirmed annual savings of $\$ 760,000$ and 95,000

MMBtu. It was also calculated that if similar burners were installed in the other lines, burner efficiency in each line would similarly increase. Total estimated annual energy and cost savings for retrofitting the four other lines was approximately $320,000 \mathrm{MMBtu}$ and $\$ 2.57$ million.

\section{- Recover Waste Heat from Pellet Coolers - A} significant amount of waste heat at between the pellet coolers without being recovered. By installing absorption chillers the plant could recover this waste heat and use it for space heating and cooling. The assessment estimated that if only $10 \%$ of this waste heat was recovered for space heating for the winter months, the plant would save about $\$ 1.1$ million and 138,000 MMBtu annually.

\section{- Recover Waste Heat from Water Used to} Cool Bearings-The assessment also found that waste heat from the water used to cool the bearings during kiln rotation was not being recovered. Recovering waste heat from the cooling water was estimated to save $\$ 893,000$ and 112,000 MMBtu per year.

\section{- Recover Waste Heat from Drying and Pre-} heating Processes-Another source of waste heat that was unrecovered was from the drying and preheat process. If the plant recovered the waste heat from this source it would save more than 3,000 MMBtu and \$24,000 annually.

- Install Recuperator-At the time of the assessment all but one of the process lines was equipped with stack recuperators. The assessment showed that by installing a similar recuperator on that line to preheat combustion air, the plant would achieve annual energy savings of approximately 221,000 MMBtu and $\$ 1.8$ million per year.

If implemented, the total annual energy cost approximately $\$ 10$ million. $600^{\circ} \mathrm{F}$ and $900^{\circ} \mathrm{F}$ was being exhausted from savings from these measures was estimated at

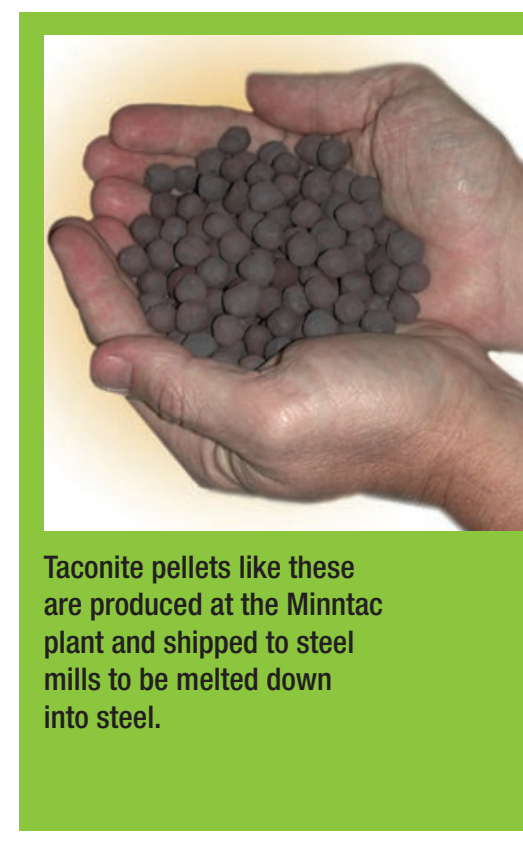




\section{Results}

During the assessment, the performance of the new burners was analyzed by the Energy Expert using the PHAST to decide how beneficial it would be for the plant to install such burners in the other kilns. It was determined that burner efficiency in the line with the new burners increased by $5 \%$ and confirmed that the new burners were yielding annual energy savings of approximately 95,000 MMBtu, representing about $10 \%$ of the natural gas used in that process line.

Furthermore, the assessment team established that with the new burners nitric oxide emissions from that kiln were $6 \%$ lower. Also, unscheduled production shutdowns due to the burner system were greatly reduced and the amount of time needed to clean the slag inside the kiln was reduced by two-thirds, saving approximately $\$ 30,000$ in annual maintenance labor costs. With total savings of $\$ 790,000$ and installation costs of $\$ 1.2$ million, the plant achieved a simple payback of 1.5 years.

The success of the new, high-efficiency burners has had a positive effect on future energyefficiency efforts at U. S. Steel. Additional Save Energy Now assessments were performed at other U. S. Steel plants in Indiana and Michigan in 2006 and 2007. Estimated annual energy savings from implemented measures at those plants are approximately 863,000 MMBtu and more than $\$ 6$ million.

At the Minntac plant, new burners will be installed on three other kilns; two in 2008 and one in 2009, and a Save Energy Now assessment is scheduled for the fan systems in the plant. In addition, the plant is studying the feasibility of recovering waste heat from the pellet coolers and installing a recuperator on the process line that does not currently have one.

\section{Lessons Learned}

Upgrading process heating systems with highefficiency components can deliver more than energy savings. At U. S. Steel's Minntac plant, aging burners in a large kiln consumed excessive amounts of natural gas and led to shut downs that sometimes damaged other equipment. By installing high-efficiency burners in this kiln, the Minntac plant achieved strong energy savings and several non-energy benefits including lower emissions, reduced production shut downs, and lower maintenance labor costs. The Save Energy Now assessment validated this project and provided further motivation for future burner system upgrades.

In addition to PHAST, other DOE software tools can be used to analyze industrial systems and processes and generate significant energy savings opportunities. These include: AIRMaster+, the Fan System Assessment Tool (FSAT), MotorMaster+, the Steam System Assessment Tool (SSAT), the Pumping System Assessment Tool (PSAT), and 3E Plus ${ }^{\circledR}$.

\section{About Save Energy Now \\ Through Save Energy Now, DOE's Industrial Technolo- gies Program (ITP) helps industrial plants operate more efficiently and profitably by identifying ways to reduce energy use in key industrial process systems. Visit www.eere.energy.gov/industry/saveenergynow for more information.}

\section{A Strong Energy Portfolio for a Strong America}

Energy efficiency and clean, renewable energy will mean a stronger economy, a cleaner environment, and greater energy independence for America. Working with a wide array of state, community, industry, and university partners, the U.S. Department of Energy's Office of Energy Efficiency and Renewable Energy invests in a diverse portfolio of energy technologies.

For more information, contact the EERE Information Center, 1-877-EERE-INF (1-877-337-3463), www.eere.energy.gov And visit the DOE Industrial Technologies Program home page: www. eere.energy.gov/industry 